\title{
Microcracking and the failure of polycrystalline ice under triaxial compression
}

\author{
P. KALIFA, \\ Institute for Marine Dynamics (NRCC), St. John's, Newfoundland A1B 3T5, Canada \\ G. Ouillon and P. Duval \\ Laboratoire de Glaciologie et Géophysique de l'Environnement (CNRS), \\ 38402 Saint-Martin-d'Hères Cedex, France
}

\begin{abstract}
Triaxial and uniaxial compression tests have been carried out at $-10^{\circ} \mathrm{C}$ on granular ice in order to study the role of microcracking on failure in the ductile-brittle transition zone. In the triaxial tests, the effect of confining pressure and strain rate on the crack population, as well as on strength and strain at the peak stress, was investigated. In the uniaxial tests, we measured the evolution of elastic and non-elastic components of deformation with the stress-strain history. The concept of effective stress, with a single scalar damage variable, was used to calculate the effect of microcracking on the strain components.
\end{abstract}

\section{INTRODUCTION}

Polycrystalline ice exhibits both brittle and ductile behavior. At low strain rates, strength increases with strain rate, following a power law. In constant strain-rate tests, the maximum stress is reached at strain close to $10^{-2}$ (Mellor and Cole, 1982). At high strain rates (typically higher than $10^{-3} \mathrm{~s}^{-1}$ in uniaxial compression), the material is purely brittle and the failure stress is relatively insensitive to strain rate (Cole, 1987). However, the failure mode is highly sensitive to the ice/end-cap interface conditions (Lasonde and others, 1988); it has been reported to be either axial splitting, shear faulting or explosive failure (Schulson, 1991). Fracture occurs at very low strains (Schulson, 1987). In the intermediate range of strain rates, microcracking occurs and a peak stress is observed. Strain in excess of $5 \times 10^{-2}$ can be reached without macroscopic failure (Meyssonnier and Duval, 1989; Stone and others, 1989). Ice exhibits a semi-ductile behavior.

The strain rate marking the ductile-brittle transition depends on stress state, temperature and grain-size (Schulson and Cannon, 1984; Cole, 1987). By inhibiting cracking activity, a moderate confining pressure shifts the ductile-brittle transition towards higher strain rates and the strength of ice increases (Jones, 1978, 1982; Murrell and others, 1990).

The paper is concerned with the strength of freshwater isotropic granular ice under uniaxial and triaxial compression, in the range of strain rate where ice exhibits a semi-ductile behavior. It focuses on the influence of microcracks on ice deformation.
Continuum-damage mechanics provides a suitable framework for the development of constitutive models describing the progressive degradation of the mechanical properties of ice undergoing homogeneously distributed microcracking. It has only recently been introduced into the field of ice mechanics (Sjolind, 1987; Karr and Choi, 1989; McKenna and others, 1989; Meyssonnier and Duval, 1989). Damage models incorporate kinetic equations describing the damage evolution, and equations giving the mechanical behavior of the material at a given state of damage.

Concerning the damage growth, recent work has shown the important role of the delayed elastic strain in the nucleation process (Sinha, 1984; Schulson, 1987; Kalifa and others, 1989). Besides, observations using either visual or accoustic emission techniques have shown that maximum cracking activity occurs before the minimum creep rate (or the peak stress for constant strainrate tests) is reached, and that further evolution, especially the development of heterogeneities, depends on the stress level (or strain rate) (Gold, 1970a, b; St Lawrence and Cole, 1982; Cole and St Lawrence, 1984; Cole, 1986, 1991). This was also observed under triaxial compression (Murrell and others, 1991). However, many more quantitative results on the crack population under uniaxial and triaxial compression are required to model the evolution of damage with the stress-strain history.

Concerning the mechanical response of damaged ice, two recent works have focused on the semi-ductile behavior of granular ice. Meyssonnier and Duval (1989) have shown that the creep rate of damaged ice could be 500 times higher than that of virgin ice, but that 
the exponent of the power law $(n=3)$ was unchanged. These results were discussed by using the continuumdamage mechanics approach. Sinha (1988) incorporated the effect of cracking in his non-linear visco-elastic creep equation. He assumed that the delayed elastic and elastic strain components were not affected by damage. The effect of cracks on the viscous strain rate was analysed by adopting Weertman's (1969) model for dilute concentration of non-interacting cracks.

The present work describes two main series of experiments, both focused on the semi-ductile behavior of granular ice. In the first one, we carried out constant crosshead velocity tests under confining pressure. The critical stress and strain at the peak stress were determined, and the structural state of ice at this stage was characterized. The aim of the second series was to study the influence of damage on the behavior law, in uniaxial compression, at a strain rate of $5 \times 10^{-4} \mathrm{~s}^{-1}$. Tests were halted at various levels of damage and recovery strain components were measured at unloading. Besides these two series, constant strain-rate tests and creep tests were performed on virgin specimens in order to determine the mechanical constants of the ice used.

Before describing our experimental procedure and discussing the results, we will present the rheological method with which we described the behavior of virgin ice, as well as the concept we used to incorporate the effect of damage on the constitutive equations.

\section{CONSTITUTIVE EQUATIONS AND EFFECT OF DAMAGE}

In most models describing the creep behavior of polycrystalline ice, strain $(\varepsilon)$ is assumed as the sum of an instantaneous elastic component $\varepsilon^{\mathrm{e}}$, and two time-dependent components: the delayed elastic strain (or visco-elastic strain) $\varepsilon^{\mathrm{d}}$, and the viscous strain $\varepsilon^{\mathrm{v}}$. Several rheological models have been proposed to describe the creep behavior of polycrystalline ice (Le Gac and Duval, 1980; Ashby and Duval, 1985; Shyam Sunder and Wu, 1989). A simple rheological model, showing both transient and steady-state creep, is the Burgers body: a Maxwell element and a Kelvin-Voigt element in series (Fig. 1). The Burgers body, characterized by four parameters, has been adopted in this paper. A more realistic model should include several Kelvin-Voigt elements as shown in Figure 1.

The constitutive equation associated with the Burgers body is:

$$
\begin{gathered}
\varepsilon(t)=\frac{\sigma(t)}{\mathrm{E}_{\mathrm{e}}}+\exp (-\alpha t) \int_{0}^{t} \frac{\sigma\left(t^{\prime}\right)}{\eta} \exp \left(\alpha t^{\prime}\right) \mathrm{d} t^{\prime} \\
+A \int_{0}^{t}\left[\sigma\left(t^{\prime}\right)\right]^{n} \mathrm{~d} t^{\prime}
\end{gathered}
$$

where $\alpha=\mathrm{E}_{\mathrm{d}} / \eta, \mathrm{E}_{\mathrm{d}}$ is visco-elastic modulus, $\eta$ is viscosity, $\mathrm{E}_{\mathrm{e}}$ is Young's modulus, $A$ and $n$ are the constants of Glen's power law. Since this model does not incorporate the influence of the microstructure or temperature, the parameters of the equation have to be determined for every case. To take into account the effect of damage on the constitutive equations, we used the concept of effective stress: a damaged volume of material under

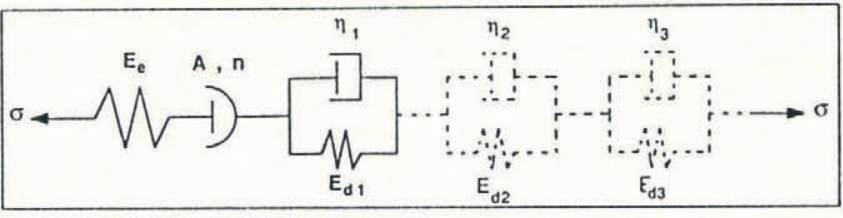

Fig. 1. Rheological model used to represent the creep behavior of granular ice.

the applied stress $\sigma$ shows the same strain response as the undamaged one submitted to the effective stress $\tilde{\sigma}$ (Chaboche, 1988).

In the general case, the effective stress tensor $\tilde{\boldsymbol{\sigma}}$ is related to the applied stress tensor $\boldsymbol{\sigma}$ through the relationship:

$$
\tilde{\sigma}=\frac{\sigma}{1-\mathrm{D}}
$$

where $\mathrm{D}$ is the damage tensor. When damage is isotropic, D becomes a scalar variable $D$. Although damage is not isotropic in ice, we assumed that $\mathrm{D}$ is a scalar. When there is no damage, $D=0$ and $\tilde{\sigma}=\sigma$. When failure occurs, $D=1$.

Moreover, by using a single damage variable, we assumed that the effect of damage is the same for the elastic, delayed elastic and viscous strain components.

\section{EXPERIMENTAL PROCEDURE}

\section{Specimens}

All tests were carried out at $-10.0 \pm 0.2^{\circ} \mathrm{C}$ on fairly bubble-free, isotropic granular ice (Ih ice) made at the laboratory. Specimens exhibited a mean grain-size of either $2 \mathrm{~mm}$ (called in this paper "fine"-grained ice) or $5 \mathrm{~mm}$ ("coarse"-grained ice). The average grain-size $\left(d_{\mathrm{g}}\right)$ was estimated using the relationship (Dieter, 1976):

$$
d_{\mathrm{g}}=\left(6 / \pi N_{\mathrm{a}}\right)^{\frac{1}{2}}
$$

where $N_{\mathrm{a}}$ is the number of grains per unit area. The specimens were machined to obtain cylinders of $40 \mathrm{~mm}$ diameter for triaxial tests and $60 \mathrm{~mm}$ for uniaxial tests. Their height was twice their diameter. For triaxial tests, the specimen dimensions were limited by the capability of the testing machine and by the geometry of the confinement cell. In all tests, the end caps were smooth stainless steel platens, and the specimens were not bonded to them. Before testing, the specimens were pre-loaded at $\approx 0.5 \mathrm{MPa}$ for $10 \mathrm{~min}$ in order to smooth the ends of the specimens. The very small deformation induced by this pre-loading was neglected.

\section{Triaxial tests}

The triaxial tests were performed on a $40 \mathrm{kN}$ electromechanical press provided with a displacement control mechanism of a platen, and which supplied a uniaxial stress to a specimen. The stiffness of the frame was measured as $0.23 \mathrm{MN} \mathrm{mm}^{-1}$. An isotropic pressure, obtained by the compression of a perfectly transparent silicon oil in a confinement cell, was superimposed. This cell included a compensation piston connected to the main piston in order to ensure a constant fluid pressure. A more detailed description of this cell was given in a previous paper 
(Kalifa and others, 1989). The walls of the cell were provided with four windows that enabled visual monitoring of the specimens during the tests, an important feature for cracking studies. Cracks were rendered visible by the reflection of a light source on their faces.

The machine was equipped with a strain-gauge load cell providing a measurement of the axial load. The main stresses $\sigma_{1}, \sigma_{2}, \sigma_{3}$ on the specimen are:

$$
\begin{aligned}
& \sigma_{1}=(F / S)+P_{\mathrm{c}} \\
& \sigma_{2}=\sigma_{3}=P_{\mathrm{c}}
\end{aligned}
$$

where $F$ is the axial force, $S$ the cross-sectional area of the specimen and $P_{\mathrm{c}}$ the confining pressure. Note that compressive stresses are treated as positive, and that $\sigma_{1}$ is the greatest stress. An LVDT transducer fixed to the cap of the confinement cell measured the displacement of the main piston $\left(d_{\mathrm{p}}\right)$, from which we approximated the axial strain of the specimen: $\varepsilon=d_{\mathrm{p}} / h$ where $h$ is the nominal specimen height.

The cross-head velocity was varied so that the nominal strain rate ranged between $2.5 \times 10^{-5}$ and $5 \times 10^{-3} \mathrm{~s}^{-1}$. However, the actual strain rate did not remain constant during the tests: the initial strain rate was smaller than the nominal value, which was reached close to the peak stress. For each strain rate, the confining pressure was varied between 0 and $10 \pm 0.2 \mathrm{MPa}$. It was monitored on a dial and no variation was noticed during the tests.

Visual monitoring of the samples during the tests gave us a general idea of the initiation and the evolution of cracking activity. Special attention was given to cracking homogeneity and to ice/end-cap interface effects. A quantitative characterization of the structural state of ice at the peak stress was subsequently obtained by systematically stopping the tests at this event and immediately analyzing sections taken from the specimens. This analysis was performed only on coarse-grained specimens. The peak stress was identified by direct observation of the force measurement. When this step was reached, the confining pressure was immediately and slowly reduced to zero in order to avoid crack closure. A quick release of confining pressure would have produced new cracks. This undesired specimen alteration was apparently negligible if the procedure was done carefully. Three sections of a thickness of $2 \mathrm{~mm}$ were taken from the central one-third of the specimens: two were horizontal (perpendicular to the $\sigma_{1}$ axis) and the third one was vertical. This analysis provided qualitative results on orientation, length and nucleation site of the cracks, which were discussed in a previous paper (Kalifa and others, 1989). Crack density was measured on the horizontal sections and observed through a microscope under polarized light. We counted the cracks intersecting the upper surface of the section and a straight-line segment. This operation was repeated eight times, and 40-60 cracks were counted on each section. We then deduced a linear density of cracks $\rho_{\mathrm{L}}$ :

$$
\rho_{\mathrm{L}}=N_{\mathrm{c}} / L \quad\left(\mathrm{~mm}^{-1}\right)
$$

where $N_{\mathrm{c}}$ is the number of cracks counted in the section and $L$ is the total segment length. To calculate the number of cracks per grain $\left(\rho_{\mathrm{g}}\right)$, we assumed that the cracks had a mean length equal to the average grain diameter $\left(d_{\mathrm{g}}\right)$. Then,

$$
\rho_{\mathrm{g}}=\rho_{\mathrm{L}} \times d_{\mathrm{g}} \quad(\text { per grain }) .
$$

Note that this calculation was done with no regard to the crack-nucleation sites. We preferred to use this procedure rather than to estimate a superficial crack density, because the latter was high enough to enable crack linkage. Then, the distinction between a single crack and two linked cracks was ambiguous.

\section{Uniaxial tests}

The uniaxial test series was performed on a second machine: a closed-loop controled machine with a capacity of $0.5 \mathrm{MN}$ and a theoretical rigidity of $1.68 \mathrm{MN} \mathrm{mm}^{-1}$. This machine was equipped with a piezoelectric load cell providing a measurement of the axial load. Strain was measured with LVDTs, using two methods: the transducer measured either the relative displacement of the platens or was fixed directly on the central part of the specimen. A light melting-freezing process assured the attachment of the grips on the surface of the specimen. The grips were connected together during this procedure in order to prevent misalignment and removed before testing.

For both triaxial and uniaxial tests, the analog outputs of all the transducers were recorded on a strip-chart recorder. Stress-strain curves were then generated by taking data points from these records and using a leastsquares fitting method.

Uniaxial tests were conducted at a constant piston velocity. Since the height of the specimen varied slightly from test to test, the actual strain rate was also altered. The average strain rates are, for fine-grained ice $\dot{\varepsilon}=$ $(5.6 \pm 0.7) \times 10^{-4} \mathrm{~s}^{-1}$, and for coarse-grained ice $\dot{\varepsilon}=$ $(5.9 \pm 1.4) \times 10^{-4} \mathrm{~s}^{-1}$.

The tests were stopped at various stages on the stressstrain path, before or after the peak stress. Strain recovery after unloading was measured. Since delayed elastic strain takes a very long time to recover fully, strain was expressed as

$$
\varepsilon=\varepsilon^{\mathrm{e}}+\varepsilon^{\mathrm{c}}
$$

where $\varepsilon^{\mathrm{c}}=\varepsilon^{\mathrm{d}}+\varepsilon^{\mathrm{v}}$ is the non-elastic or complementary strain. However, a lower bound of $\varepsilon^{\mathrm{d}}$ and an upper bound of $\varepsilon^{v}$ were estimated. Before each test, a "stress-impulse" test was performed in order to measure Young's modulus of virgin ice. The specimen was loaded at $10^{-3} \mathrm{~s}^{-1}$, then unloaded very fast. The maximum stress $\sigma_{\mathrm{f}}$ never exceeded $3 \mathrm{MPa}$ in order to prevent cracking. As shown by the strain measurement, the specimen exhibited a linear elastic behavior. Young's modulus $\mathrm{E}_{\mathrm{e}}$ was then deduced:

$$
\mathrm{E}_{\mathrm{e}}=\sigma_{\mathrm{f}} / \varepsilon_{\mathrm{f}}
$$

where $\varepsilon_{\mathrm{f}}$ is the deformation instantaneously recovered at unloading.

\section{Creep tests}

Creep tests were carried out on virgin ice in order to determine visco-elastic and viscoplastic constants. A third 
apparatus was used for these tests: the constant load was provided by means of dead weights hung at the extremity of a lever. The strain was measured directly on the specimen. The applied load was between 1.5 and 1.7 $\mathrm{MPa}$ and, after $2-2.5 \mathrm{~h}$, the secondary creep was virtually reached. Assuming that the secondary creep rate $\left(\dot{\varepsilon}_{\min }\right)$ is given by Glen's law:

$$
\dot{\varepsilon}_{\min }=A \sigma^{n} \quad \text { with } n=3 \text {, }
$$

we deduced $A$ from the tests. As well, the viscous defor-

Table 1. Experimental values of the mechanical constants used in the constitutive equation (Equation (3)), for both grain-sizes

\begin{tabular}{cccccc} 
Grain-size & $E_{0}$ & $E_{\mathrm{d}}$ & $\eta$ & $A$ & $n$ \\
$\mathrm{~mm}$ & $\mathrm{GPa}$ & $\mathrm{GPa}$ & $\mathrm{GPa} \mathrm{s}$ & $\mathrm{MPa}^{-3} \mathrm{~s}^{-1}$ & \\
\hline 2 & 6.31 & 1.3 & 25 & $5.72 \times 10^{-8}$ & 3 \\
5 & 6.5 & 1.3 & 25 & $3.6 \times 10^{-8}$ & 3 \\
\hline
\end{tabular}

mation was calculated as

$$
\varepsilon^{\mathrm{v}}=\dot{\varepsilon}_{\min } t_{\mathrm{f}}
$$

where $t_{\mathrm{f}}$ is test duration. The linear elastic strain $\left(\varepsilon^{\mathrm{e}}\right)$ was also measured at unloading. The delayed elastic component $\left(\varepsilon^{\mathrm{d}}\right)$ was merely deduced:

$$
\varepsilon^{\mathrm{d}}=\varepsilon^{\mathrm{f}}-\varepsilon^{\mathrm{v}}-\varepsilon^{\mathrm{e}}
$$

where $\varepsilon_{\mathrm{f}}$ is the total strain at the end of the test. A visco-elastic modulus $\mathrm{E}_{\mathrm{d}}$ was then calculated:

$$
\mathrm{E}_{\mathrm{d}}=\sigma / \varepsilon^{\mathrm{d}}
$$

\section{RESULTS AND ANALYSIS}

\section{Mechanical constants of virgin ice}

Table 1 summarizes the average mechanical constants of virgin ice for both grain-sizes. Elastic moduli for each test are given in Table 2. The large standard deviation of the elastic moduli may be partly due to the method of measurement: very small strains are involved in the stress-impulse tests and, since only one transducer was fixed on the specimen, a small non-parallelism of the ends could induce a large inaccuracy. Also, one notes that strain measurements made on the specimen gave a larger value of the modulus. The effect of grain-size is not noticeable; it is within the standard deviation. The

Table 2. Results for uniaxial tests. The second column indicates the type of strain measurement: "platens" means that strain was measured between the platens, "specimen" means that the transducer

\begin{tabular}{|c|c|c|c|c|c|c|c|c|c|c|}
\hline \multirow[t]{2}{*}{ Spec.\# } & \multirow{2}{*}{$\begin{array}{c}\text { Type of } \\
\text { measurement }\end{array}$} & \multicolumn{2}{|c|}{ Strain rate } & \multirow{2}{*}{$\begin{array}{c}\sigma_{\mathrm{p}} \\
\mathrm{MPa}\end{array}$} & \multirow{2}{*}{$\begin{array}{l}\varepsilon_{\mathrm{p}} \\
\times 10^{-3}\end{array}$} & \multirow{2}{*}{$\begin{array}{c}\sigma_{\mathrm{f}} \\
\mathrm{MPa}\end{array}$} & \multirow{2}{*}{$\begin{array}{c}\varepsilon_{\mathrm{f}} \\
\times 10^{-3}\end{array}$} & \multirow{2}{*}{$\begin{array}{l}\varepsilon_{\theta} \\
\times 10^{-3}\end{array}$} & \multirow{2}{*}{$\begin{array}{c}\varepsilon_{\mathrm{c}} \\
\times 10^{-3}\end{array}$} & \multirow{2}{*}{$\begin{array}{c}E_{0} \text { (initial) } \\
\mathrm{GPa}\end{array}$} \\
\hline & & & $s^{-1}$ & & & & & & & \\
\hline \multicolumn{11}{|c|}{ Fine-grained ice $\left(d_{\mathrm{g}}=2 \mathrm{~mm}\right)$} \\
\hline E10 & Platens & 5.3 & $\times 10^{-4}$ & 9.05 & 3.47 & - & 3.83 & 1.49 & 2.36 & 4.4 \\
\hline E14 & Platens & 6.7 & $\times 10^{-4}$ & - & - & 9.30 & 2.31 & 1.33 & 0.98 & 7.3 \\
\hline E14-2 & Platens & 5.9 & $\times 10^{-4}$ & - & - & 6.50 & 1.87 & 1.09 & 0.78 & 6.6 \\
\hline E16 & Platens & 5.4 & $\times 10^{-4}$ & - & - & 9.45 & 2.85 & 1.66 & 1.19 & 5.7 \\
\hline E18 & Specimen & 4.8 & $\times 10^{-4}$ & - & - & 7.95 & 1.72 & 1.05 & 0.67 & 7.7 \\
\hline E23 & Specimen & 6.1 & $\times 10^{-4}$ & 8.45 & 2.98 & - & 3.71 & 1.09 & 2.62 & - \\
\hline \multicolumn{11}{|c|}{ Coarse-grained ice $\left(d_{\mathrm{g}}=5 \mathrm{~mm}\right)$} \\
\hline E4 & Platens & 4.9 & $\times 10^{-4}$ & - & - & 8.35 & 2.57 & 1.16 & 1.44 & - \\
\hline E5 & Platens & 6.7 & $\times 10^{-4}$ & 7.40 & 1.86 & - & 3.98 & 1.06 & 2.92 & - \\
\hline E6 & Platens & 4.1 & $\times 10^{-4}$ & 8.80 & 2.67 & - & 3.10 & 1.90 & 1.20 & 5.2 \\
\hline E9 & Platens & 4.7 & $\times 10^{-4}$ & - & - & 8.70 & 2.12 & 1.43 & 0.69 & 5.1 \\
\hline $\mathrm{E} 17$ & Specimen & 7.5 & $\times 10^{-4}$ & - & - & - & 2.23 & 1.05 & 1.18 & 9.1 \\
\hline E24 & Specimen & 7.9 & $\times 10^{-4}$ & 8.30 & 2.94 & 8.30 & 3.38 & 1.06 & 2.32 & - \\
\hline
\end{tabular}
was fixed on the central part of the specimen. In the other columns, the subscript $p$ is used for measurement at the peak stress, while the subscript $f$ is related to the end of the tests. As well, $\varepsilon^{e}$ and $\varepsilon^{c}$ are the elastic and complementary components, respectively, at the end of the tests 
Kalifa and others: Failure of polycrystalline ice under triaxial compression
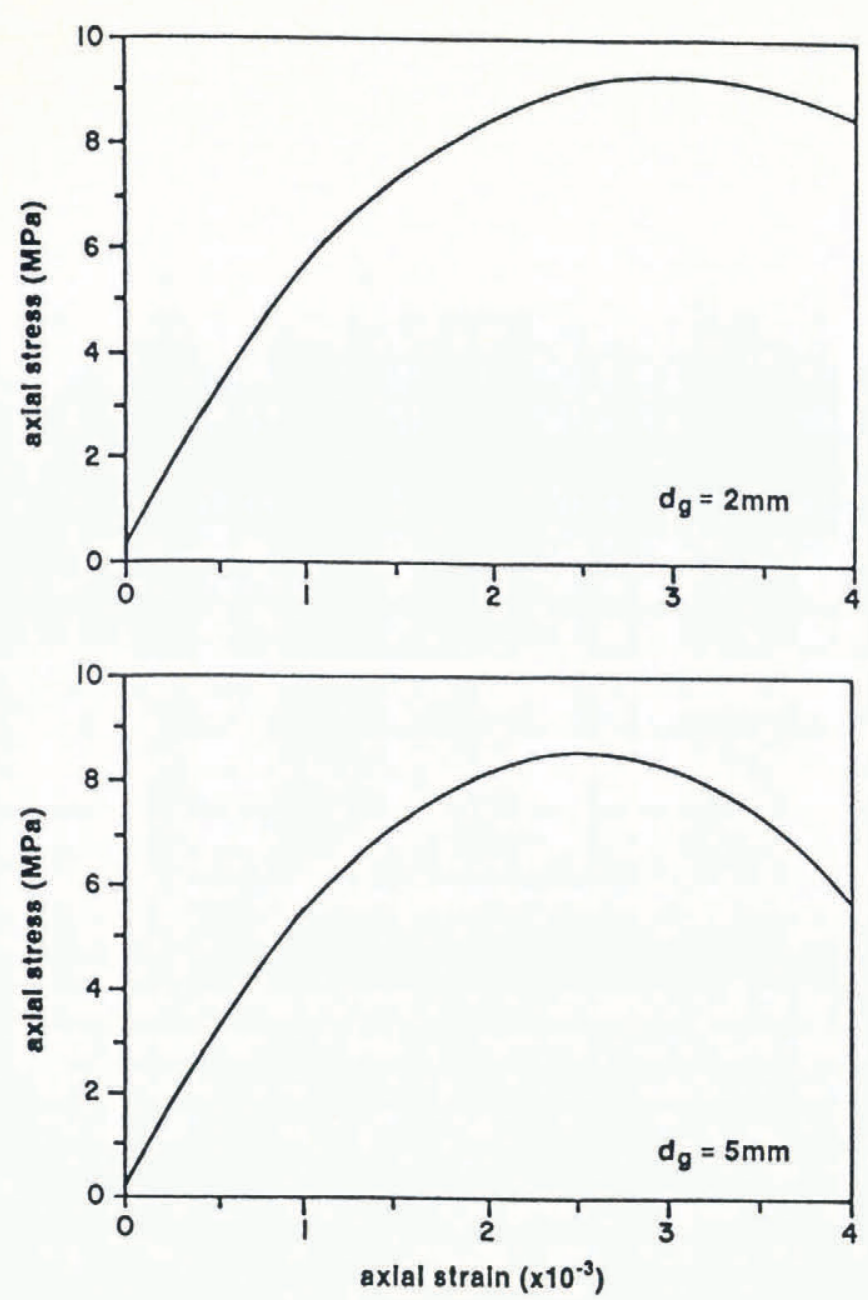

Fig. 2. Composite stress-strain curves for uniaxial tests, generated using the analog records of all the tests (six tests for each grainsize).

low value of the experimental moduli compared to the theoretical value $(9.5 \mathrm{GPa})$ may also be a result of the procedure for making the granular ice; the very small bubbles it contains may reduce the elastic modulus.

The tests gave exactly the same visco-elastic modulus for both grain-sizes. The variation of $\eta$ with grain-size was also very small.

\section{Uniaxial tests}

Test conditions and results are summarized in Table 2.

For each grain-size, a composite $\sigma-\varepsilon$ curve combining all six tests was generated, using a least-squares fitting method. The curves are plotted in Figure 2. The equations are:

fine grains: $\quad \sigma=0.26+6.31 \varepsilon-1.25 \varepsilon^{2}+3.8 \times 10^{-2} \varepsilon^{3}$,

coarse grains: $\sigma=0.11+6.5 \varepsilon-1.32 \varepsilon^{2}$

where $\sigma$ is expressed in $\mathrm{MPa}$ and $\varepsilon$ in units of millistrain.

The visco-elastic viscosity was calculated for both grain-sizes, substituting Equations (13) in Equation (1), and integrating the latter between $t=0$ and $t=1 \mathrm{~s}$. These times were chosen according to the fact that the

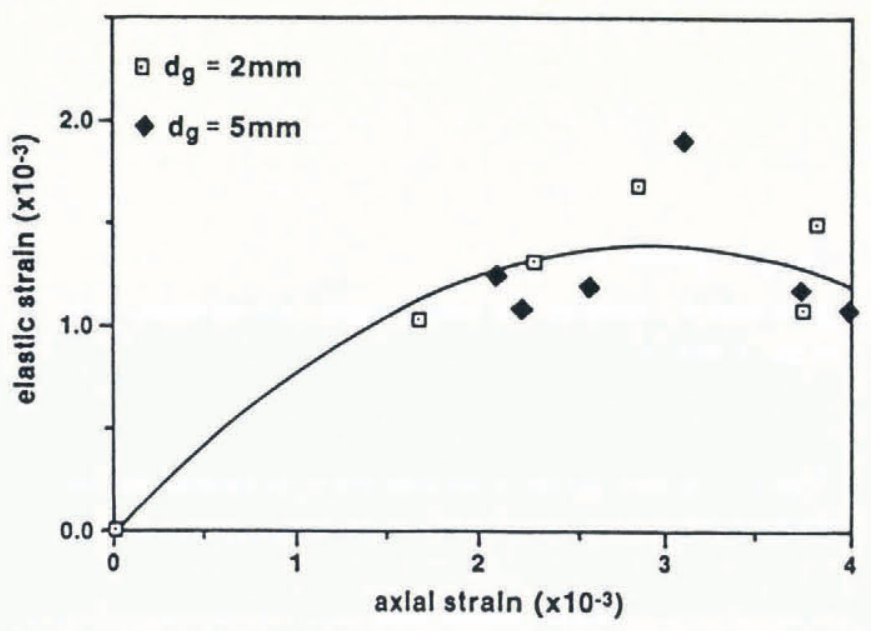

Fig. 3. Uniaxial tests: elastic component versus total strain. The polynomial fitting uses data points for both grain-sizes.

viscous strain is negligible during the first second of loading.

The strain components were measured at unloading. The linear elastic strain and the complementary strain are represented as a function of strain in Figures 3 and 4 , respectively. Since there was no evident grain-size effect, we plotted both sets of data on the same graphs. The equations of the fitting curves (using a least-squares method) are:

$$
\begin{gathered}
\varepsilon^{\mathrm{e}}=-2.47 \times 10^{-2}+0.96 \varepsilon-0.16 \varepsilon^{2}, \\
\varepsilon^{\mathrm{c}}=2.46 \times 10^{-2}+3.38 \times 10^{-2} \varepsilon+0.16 \varepsilon^{2}
\end{gathered}
$$

where $\varepsilon, \varepsilon^{\mathrm{e}}$ and $\varepsilon^{\mathrm{c}}$ are in millistrain. One notes that the linear elastic strain passes a maximum at $\varepsilon \approx 3 \times 10^{-3}$, which is very close to the strain at the peak stress. Therefore, part of the elastic deformation is released after the peak stress and transferred to the complementary component, as shown by the increase in $\varepsilon^{\mathrm{c}}$. From the data points, it is possible to give an estimate of the delayed

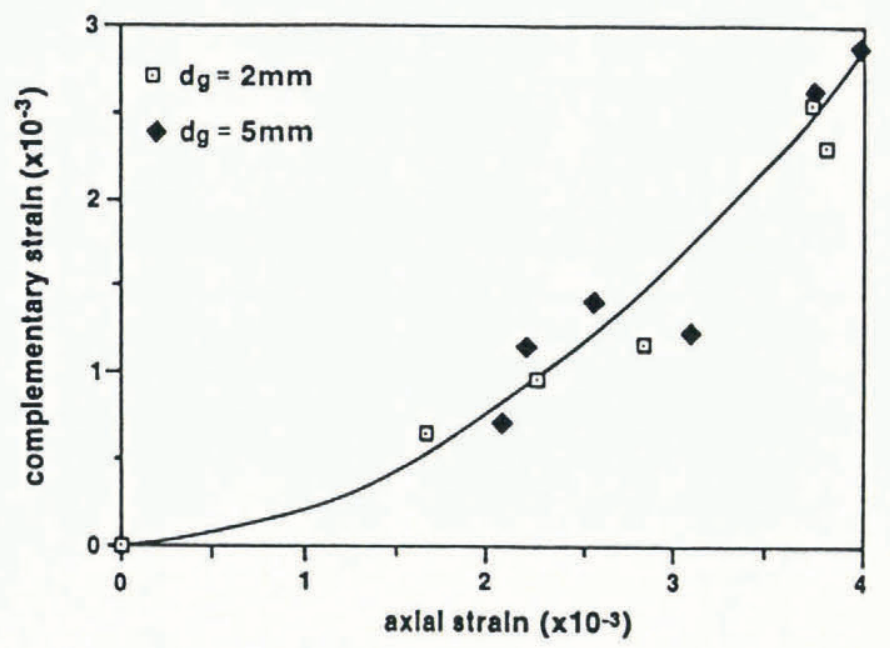

Fig. 4. Uniaxial tests: complementary component versus total strain. The polynomial fitting uses data points for both grain-sizes. 
elastic and viscous components at the peak stress:

$$
\begin{aligned}
& 1.3 \times 10^{-3}<\varepsilon^{\mathrm{d}}<1.5 \times 10^{-3}, \\
& 0.1 \times 10^{-3}<\varepsilon^{\mathrm{v}}<0.2 \times 10^{-3} .
\end{aligned}
$$

Triaxial tests

Experimental conditions and results are summarized in Tables 3 and 4.

Table 3. Results related to the peak stress for triaxial tests on fine-grained ice $\left(d_{\mathrm{g}}=2 \mathrm{~mm}\right)$

\begin{tabular}{ccccc}
\hline Spec. \# & Strain rate & $\sigma_{3}$ & $\sigma_{\mathrm{p}}$ & $\varepsilon_{\mathrm{p}}$ \\
& $\mathrm{s}^{-1}$ & $\mathrm{MPa}$ & $\mathrm{MPa}$ & $\times 10^{-3}$ \\
& & & \\
\hline
\end{tabular}

$6.9 \times 10^{-6}$

$1.9 \times 10^{-5}$

7

8-1

8-2

10

11

12-1

13-1

14.2

13-2

16

14-1

15-1

15-3

107-2

86

87

89

90

91

91-2

85

92

93

94

95

109

96

97

99

120

99-2

98

112

106

100

102

101
$2.3 \times 10^{-5}$

$2.7 \times 10^{-5}$

$5.1 \times 10^{-5}$

$5.4 \times 10^{-5}$

$7.0 \times 10^{-5}$

$8.3 \times 10^{-5}$

$1.4 \times 10^{-4}$

$4.7 \times 10^{-4}$

$4.3 \times 10^{-4}$

$5.9 \times 10^{-4}$

$5.5 \times 10^{-4}$

$4.6 \times 10^{-4}$

$5.0 \times 10^{-5}$

$5.0 \times 10^{-5}$

$5.0 \times 10^{-5}$

$5.0 \times 10^{-5}$

$5.0 \times 10^{-5}$

$5.0 \times 10^{-5}$

$1.0 \times 10^{-4}$

$1.0 \times 10^{-4}$

$1.0 \times 10^{-4}$

$1.0 \times 10^{-4}$

$1.0 \times 10^{-4}$

$1.0 \times 10^{-4}$

$5.0 \times 10^{-4}$

$5.0 \times 10^{-4}$

$5.0 \times 10^{-4}$

$5.0 \times 10^{-4}$

$5.0 \times 10^{-4}$

$5.0 \times 10^{-4}$

$5.0 \times 10^{-4}$

$5.0 \times 10^{-4}$

$1.0 \times 10^{-3}$

$1.0 \times 10^{-3}$

$1.0 \times 10^{-3}$

$1.0 \times 10^{-3}$
3.54

4.46

3.82

3.96

4.85

5.41

5.61

6.98

6.54

9.01

9.09

10.30

9.80

9.94

4.07

5.07

5.60

6.35

6.61

6.72

5.16

5.73

6.89

7.37

7.73

7.90

8.40

9.86

9.77

10.57

11.75

10.83

11.23

11.71

9.82

11.68

12.52

13.54
103

107

$1.0 \times 10^{-3}$

8

13.30

7.7

127

127
83

84

116

115-2

115

130

125

126

117

118

119

122

121

108

121-2

$1.0 \times 10^{-3}$

$2.0 \times 10^{-3}$

$2.0 \times 10^{-3}$

$2.0 \times 10^{-3}$

$2.0 \times 10^{-3}$

$2.0 \times 10^{-3}$

$2.0 \times 10^{-3}$

$2.0 \times 10^{-3}$

$5.0 \times 10^{-3}$

$5.0 \times 10^{-3}$

$5.0 \times 10^{-3}$

$5.0 \times 10^{-3}$

$5.0 \times 10^{-3}$

$5.0 \times 10^{-3}$

$5.0 \times 10^{-3}$

$5.0 \times 10^{-3}$

$5.0 \times 10^{-3}$
6.0

5.0

7.0

8.2

4.8

5.2

4.5

4.6

3.9

4.8

5.7

4.8

4.6

5.1

11.0

11.0

13.0

13.0

14.0

4.5

10.0

12.0

13.0

13.0

15.0

5.6

8.7

7.9

11.0

7.9

9.6

11.0

4.5

7.2

7.0

8.2 opaque. Murrell and others, 1991).

In all experiments, the first cracks appeared at critical stress and strain between 2 and 4 times lower than those corresponding to the peak stress. Consistent with previous work (Cole, 1986), their sizes were slightly smaller than those of grains. Further increase in stress did not result in visible crack growth, but other similar microcracks were nucleated. At strain rates higher than $10^{-4} \mathrm{~s}^{-1}$, high cracking activity made the specimens

When specimens did not fail, stress-strain curves were characterized by a peak, the width of which increased with decreasing strain rate and increasing confining pressure. For $\dot{\varepsilon}<10^{-3} \mathrm{~s}^{-1}$, cracking activity was essentially homogeneous (although it was in some cases initiated at an extremity of the specimen). Strength $\left(\sigma_{\mathrm{p}}=\sigma_{1}-\sigma_{3}\right)$ increased with strain rate following a power law, as shown in Figure 5, where $\sigma_{\mathrm{p}}$ is plotted versus the nominal strain rate on a $\log -\log$ scale diagram. In uniaxial compression, for $\dot{\varepsilon} \geq 10^{-3} \mathrm{~s}^{-1}$, failure occurred along shear bands, and strength was independent of strain rate, giving prominence to a brittle behavior. Careful examination of the rupture surfaces showed that they followed the grain boundaries. This has been confirmed by quantitative investigations performed on the thick sections (Kalifa and others, 1989), and was also reported by Cole (1987). The application of a confining pressure led to homogeneous cracking activity and prevented specimen failure. In Figure 5, the plateau observed in uniaxial compression disappeared in triaxial compression.

In Figure $6, \sigma_{\mathrm{p}}$ is plotted versus $\sigma_{3}$ for the various strain rates tested and for both grain-sizes. The rate of strength increase with $\sigma_{3}$ increased strongly with strain rate. At $5 \times 10^{-5} \mathrm{~s}^{-1}, \sigma_{\mathrm{p}}$ increased from about 4 to $7 \mathrm{MPa}$ while the confining pressure was varied from 0 to $10 \mathrm{MPa}$. At $5 \times 10^{-3} \mathrm{~s}^{-1}$, the same variation in confining pressure made $\sigma_{\mathrm{p}}$ increase from 10 to $20 \mathrm{MPa}$. These results are in good agreement with previous work (Jones, 1978, 1982;

Note that, consistent with observations in uniaxial compression by Schulson and Cannon (1984) and Cole 
Table 4. Results related to the peak stress for triaxial tests on coarse-grained ice $\left(d_{\mathrm{g}}=5 \mathrm{~mm}\right)$. The number of cracks per grain was deduced from the last two columns by dividing each number by the average grain diameter $\left(d_{\mathrm{g}}\right)$

\begin{tabular}{|c|c|c|c|c|c|c|}
\hline \multirow[t]{2}{*}{ Spec.\# } & Strain rate & \multirow{2}{*}{$\begin{array}{c}\sigma_{3} \\
\mathrm{MPa}\end{array}$} & \multirow{2}{*}{$\begin{array}{r}\sigma_{\mathrm{p}} \\
\mathrm{MPa}\end{array}$} & \multirow{2}{*}{$\begin{array}{c}\varepsilon_{\mathrm{p}} \\
\times 10^{-3}\end{array}$} & \multirow{2}{*}{$\begin{array}{c}\text { Crack } \\
\text { density } 1 \\
\mathrm{~cm}^{-1}\end{array}$} & \multirow{2}{*}{$\begin{array}{c}\text { Crack } \\
\text { density } 2 \\
\mathrm{~cm}^{-1}\end{array}$} \\
\hline & $\mathrm{s}^{-1}$ & & & & & \\
\hline 192 & $5.0 \times 10^{-5}$ & 0 & 3.66 & 2.8 & 2.0 & 2.3 \\
\hline 190 & $5.0 \times 10^{-5}$ & 2 & 6.68 & 5.7 & 1.4 & 1.5 \\
\hline 191 & $5.0 \times 10^{-5}$ & 4 & 7.28 & 8.2 & 1.9 & 2.6 \\
\hline 203 & $5.0 \times 10^{-5}$ & 6 & 5.51 & 8.5 & 0.56 & 0.83 \\
\hline 216 & $5.0 \times 10^{-5}$ & 10 & 6.57 & 10.0 & 0.59 & 0.61 \\
\hline 196 & $1.0 \times 10^{-4}$ & 0 & 4.26 & 2.8 & 2.1 & 3.5 \\
\hline 200 & $1.0 \times 10^{-4}$ & 2 & 6.02 & 5.6 & 1.2 & 1.4 \\
\hline 199 & $1.0 \times 10^{-4}$ & 4 & 7.18 & 6.7 & 1.6 & 1.4 \\
\hline 206 & $1.0 \times 10^{-4}$ & 6 & 7.53 & 8.5 & 1.4 & 1.0 \\
\hline 214 & $1.0 \times 10^{-4}$ & 10 & 7.06 & 9.1 & 0.7 & 1.1 \\
\hline 215 & $5.0 \times 10^{-4}$ & 0 & 6.21 & 3.6 & 5.5 & - \\
\hline 197 & $5.0 \times 10^{-4}$ & 0 & 7.44 & 2.3 & 1.5 & 1.9 \\
\hline 198 & $5.0 \times 10^{-4}$ & 2 & 9.31 & 6.6 & 2.4 & 2.1 \\
\hline 201 & $5.0 \times 10^{-4}$ & 4 & 9.18 & 6.1 & 0.83 & 2.8 \\
\hline 207 & $5.0 \times 10^{-4}$ & 6 & 10.19 & 7.2 & 2.2 & 1.9 \\
\hline 211 & $5.0 \times 10^{-4}$ & 10 & 9.51 & 7.8 & 1.5 & 1.8 \\
\hline 217 & $1.0 \times 10^{-3}$ & 0 & 8.09 & 1.6 & - & - \\
\hline 209 & $1.0 \times 10^{-3}$ & 4 & 10.61 & 6.9 & 3.5 & 2.7 \\
\hline 208 & $1.0 \times 10^{-3}$ & 6 & 11.50 & 8.2 & 2.5 & 2.1 \\
\hline 210 & $1.0 \times 10^{-3}$ & 10 & 11.60 & 8 & 1.9 & 3.1 \\
\hline
\end{tabular}

(1987), the strength of ice decreased slightly with increasing grain-size. This was also true in triaxial compression.

In Figure 7, crack density (as a number of cracks per grain) is plotted versus $\sigma_{3}$ for various strain rates. The ends of the vertical bars correspond to the crack density on the two horizontal sections made for each specimen. At low strain rates $\left(<10^{-4} \mathrm{~s}^{-1}\right)$, an increase in confining pressure resulted in a striking decrease in crack density at the peak stress; it passed from 1 to 0.3 cracks per grain when $P_{\mathrm{c}}$ was increased from 0 to $10 \mathrm{MPa}$. At higher confining pressures, strain at the peak stress is of the order of $10^{-2}$ (Tables 3 and 4), and grains exhibited a visible permanent deformation (at least in fine-grained ice). One has to be reminded that $10^{-2}$ is the critical strain for the onset of dynamic recrystallization (corresponding to the beginning of tertiary creep) in creep tests on ice. This indicates that ice has an essentially ductile behaviour, with very little influence of cracks. This assertion is supported by the weak increase in strength with confining pressure; Jones and Chew (1983) demonstrated that confining pressure has little effect on viscous deformation processes.

For $\dot{\varepsilon}>10^{-4} \mathrm{~s}^{-1}$, crack density did not change significantly with confining pressure, nor with strain rate. In this range of conditions, corresponding to a semi-ductile behaviour, crack density seemed to reach a critical value of 1 crack per grain at the peak stress. The noticeable effect of confining pressure was that many cracks were almost closed; the latter, still visible with a microscope, appeared greyish instead of black. When watching the specimens during the tests, we did not notice any difference between open cracks and closed cracks. Besides cracks, grains did not exhibit permanent change that was visible on the thin sections. It is remarkable that, in these types of conditions, strain at the peak stress was smaller than $10^{-2}$

\section{DISCUSSION}

The triaxial tests we performed showed that the application of a confining pressure shifts the ductile-brittle transition towards higher strain rates: strength kept increasing with strain rate beyond $10^{-3} \mathrm{~s}^{-1}$ instead of reaching a plateau; localized damage and sudden failure were replaced by homogeneous damage and semi-ductile behavior. The latter was characterized by a critical crack density at the peak stress of 1 crack per grain. Qualitative observations have shown that damage is anisotropic: cracks are preferentially oriented parallel to the most 


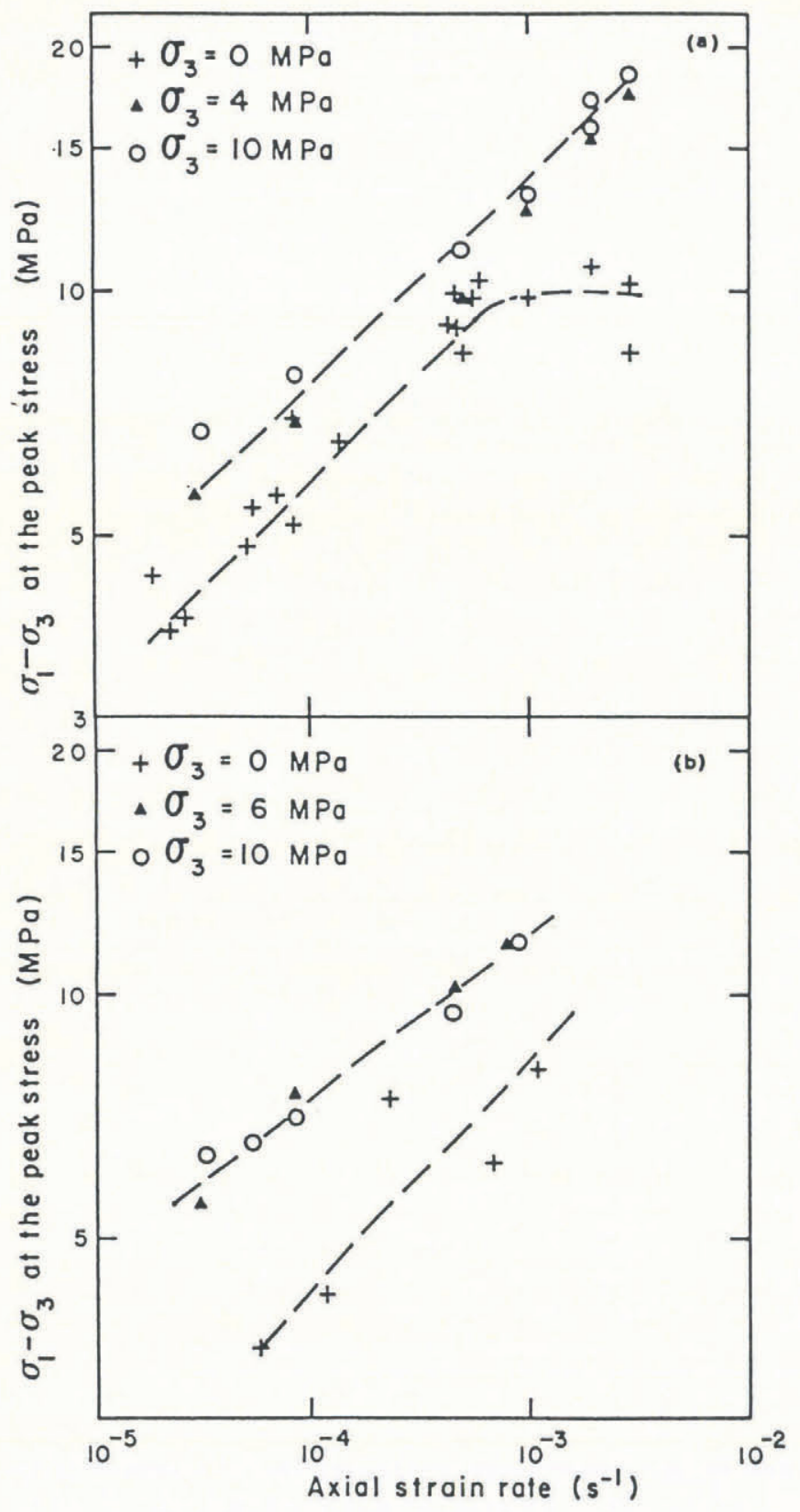

Fig. 5. Triaxial tests: maximum deviatoric stress versus strain rate for various confining pressures. (a) fine-grained ice; (b) coarsegrained ice.

compressive stress axis, although this trend weakens with increasing confining pressure (Kalifa and others, 1989). We also observed that confining pressure tends to close cracks. Jaeger and Cook (1984) calculated that only a small normal load is required for a penny-shaped crack to close. The consequences are: (a) a low alteration of the elastic modulus (Jaeger and Cook, 1984); as a result, the relative alteration of both visco-elastic and viscoplastic properties is higher. (b) An increase in the friction forces between crack faces, reducing the effective shear stresses they undergo; as a result, for the same applied stress field, the local stresses at the crack tips are lower and the propensity of cracks to propagate as well as to interact is smaller.

Assuming that the elastic modulus $\left(E_{\mathrm{e}}\right)$ is not altered by damage, the elastic component at the peak stress

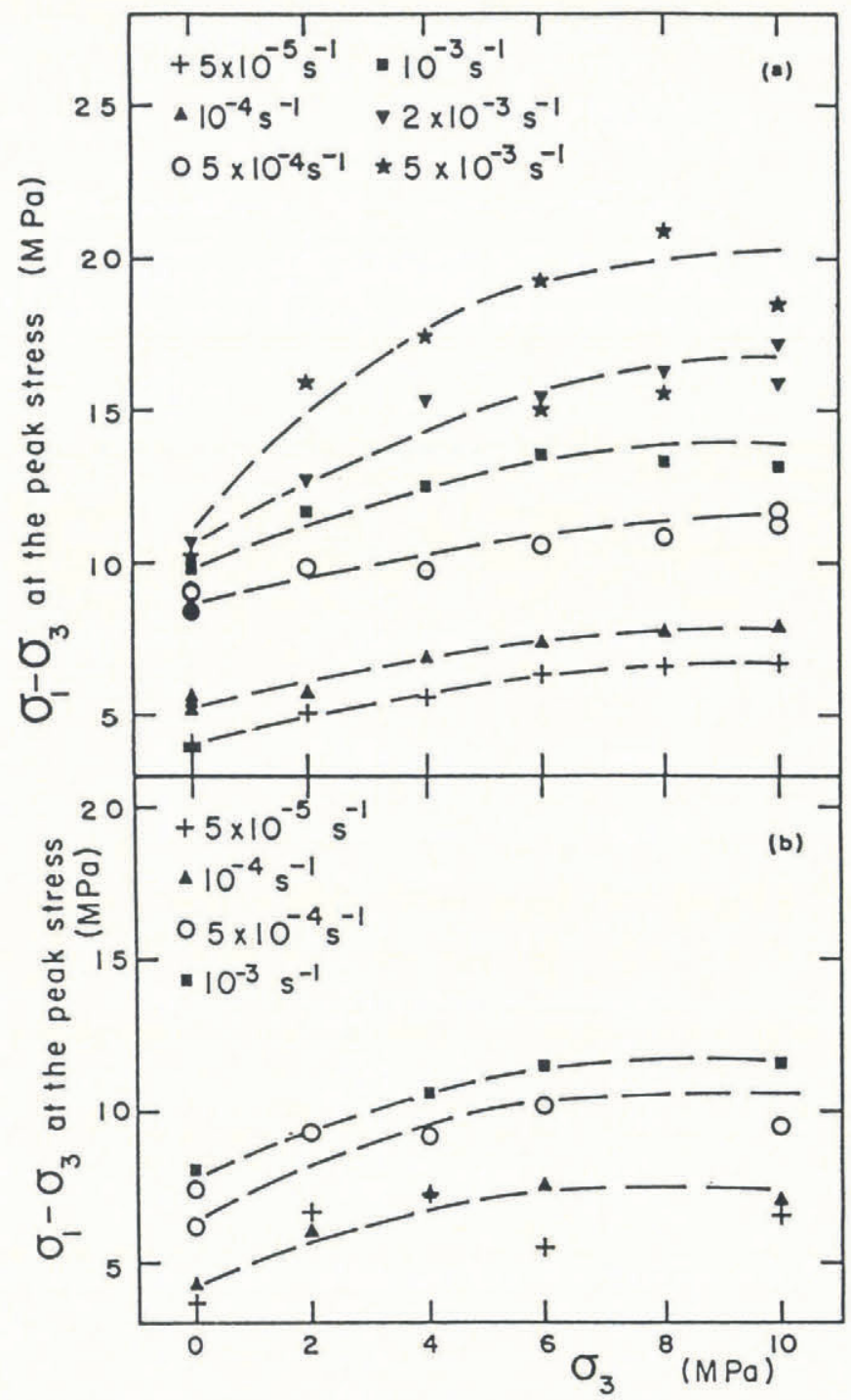

Fig. 6. Triaxial tests: maximum deviatoric stress versus confining pressure for various strain rates. (a) Fine-grained ice; (b) coarsegrained ice.

is $\varepsilon^{\mathrm{e}}=\sigma_{\mathrm{p}} / \mathrm{E}_{\mathrm{e}}$. In Figure 8 , histograms show $\varepsilon^{\mathrm{e}}$ and $\varepsilon^{c}$ as a function of strain rate and confining pressure. This calculation underestimates slightly $\varepsilon^{\mathrm{e}}$, especially at $P_{\mathrm{c}}=0 \mathrm{MPa}$. However, it is clear that, in spite of the increase in peak stress with confining pressure, inducing an increase in $\varepsilon^{\mathrm{e}}$, the ratio $\varepsilon^{\mathrm{c}} / \varepsilon^{\mathrm{e}}$ increases with confining pressure.

Using the concept of effective stress and assuming that ice behaves according to the rheological model of Figure 1 , we constructed $\tilde{\sigma}-\varepsilon, \varepsilon^{\mathrm{e}}-\varepsilon$ and $\varepsilon^{\mathrm{c}}-\varepsilon$ plots for the uniaxial compression tests. For these, we substituted $\sigma$ for $\tilde{\sigma}$ in Equation (1) and solved the new equation, $\tilde{\sigma}(t)$ being the variable. The details of the calculations are given in the Appendix. The mechanical parameters appearing in the equations are those given in Table 1. Results in uniaxial compression at $5 \times 10^{-4} \mathrm{~s}^{-1}$ are given in Figures 9 and 10 for fine grains and coarse grains, respectively. The curves $\sigma-\varepsilon$ and $\tilde{\sigma}-\varepsilon$ (Figs 9a and 10a) mingle in the first part, before damage takes place. This confirms that the mechanical parameters of virgin ice were correctly estimated. When the effect of damage 


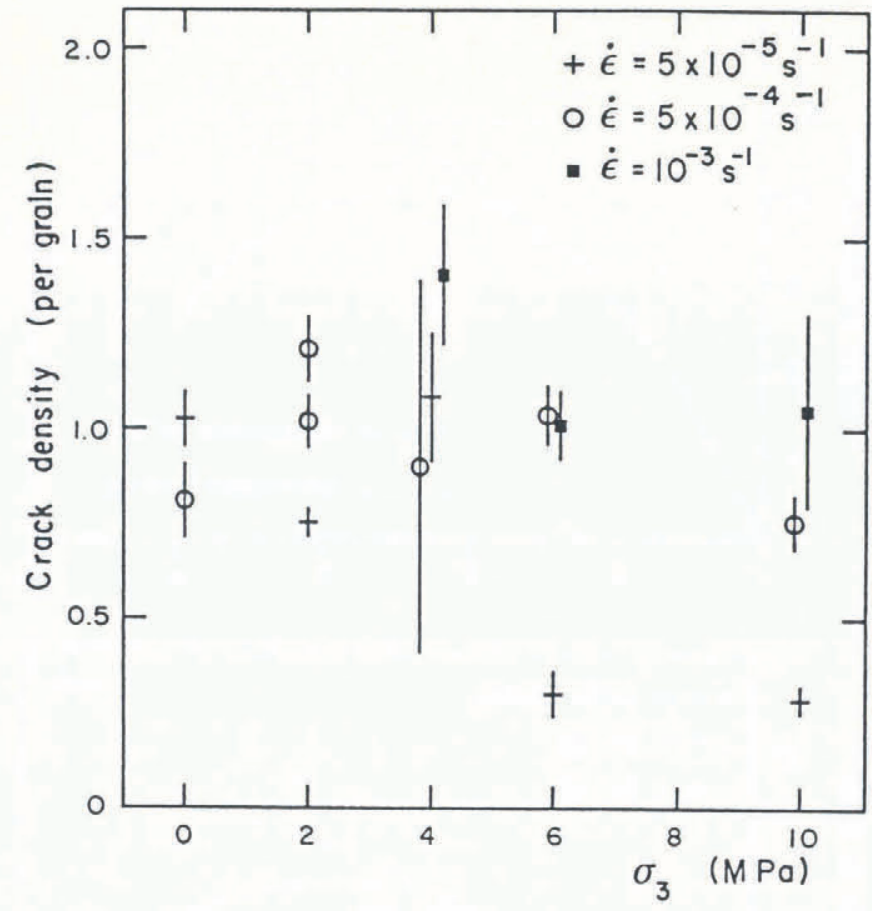

Fig. 7. Triaxial tests: crack density at the peak stress versus confining pressure for vardone for coarse-grained ice. ious strain rates. Measurements were only
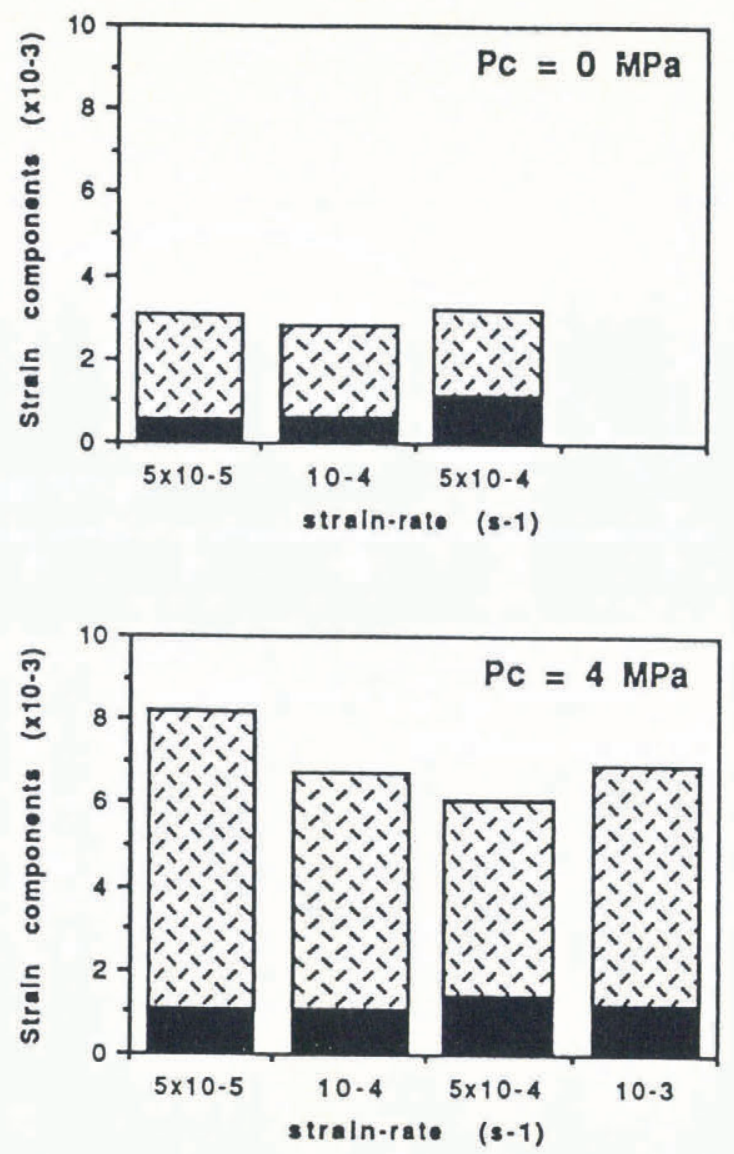

becomes significant, the curves diverge.

In Figures $9 \mathrm{~b}$ and $10 \mathrm{~b}$, we plotted $\varepsilon^{\mathrm{e}}$ calculated with the model versus $\varepsilon$, in conjunction with the curve $\varepsilon^{\mathbf{e}_{-}}$ $\varepsilon$ which would be followed by an undamaged specimen undergoing $\sigma(t)$. Also plotted are the data points. The equation of the fitting curve is Equation (14a). Similar plots are given for the complementary strain $\varepsilon^{c}$ in Figures $9 \mathrm{c}$ and 10c. The first observation is that the decrease in elastic strain observed after the peak stress is not represented by the model. However, for fine-grained ice, the data fit fairly well with the undamaged specimen curve. Thus, fine-grained ice exhibited a very slight alteration of the elastic modulus with damage. This alteration is larger for coarse-grained ice: data points are above the curve for the undamaged specimen after the peak stress, pointing out a slight decrease in elastic modulus. In Figures $9 \mathrm{c}$ and $10 \mathrm{c}$, the complementary strain given by the model is smaller than the one actually exhibited by specimens, especially after the peak stress.

Therefore, under the conditions of the study, the model overestimates the alteration of the elastic modulus and underestimates the alteration of the visco-elastic and viscoplastic properties. Below the ductile-brittle transition, the relative importance of damage on elastic and non-elastic properties depends on strain rate. Moreover, the high plastic anisotropy of ice monocrystals may emphasize the role of cracks on the non-elastic behaviour of the polycrystal; cracks are probably nucleated preferentially in those grains undergoing the highest internal stresses, i.e. that are badly oriented for basal glide. Crack nucleation should make stress distribution more homogeneous, hence stress should rise in uncracked grains. As a result, complementary deformation of the specimen should increase.

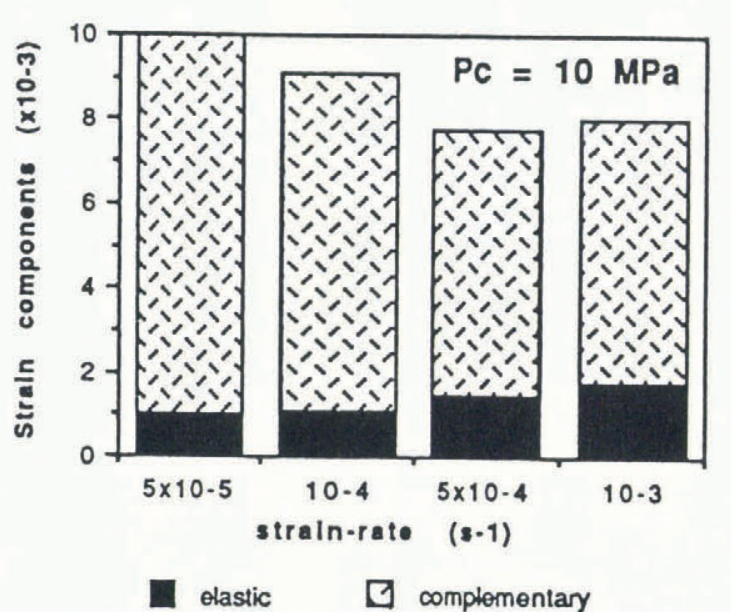

Fig. 8. Estimation of the evolution of strain components at the peak stress with confining pressure and strain rate, for coarse-grained ice. Equation (17) was used in conjunction with strain measurements.

This preliminary study shows that the effect of damage on the deformation of isotropic granular ice cannot be described by introducing the effective stress directly in the rheological equation. The results seem to support the assumption made by Karr and Choi (1989) that damage affects the elastic, delayed elastic and viscous strain components independently.

\section{CONCLUSIONS}

Uniaxial and triaxial compression tests have been carried out at $-10^{\circ} \mathrm{C}$ in order to study the semi-ductile behavior 

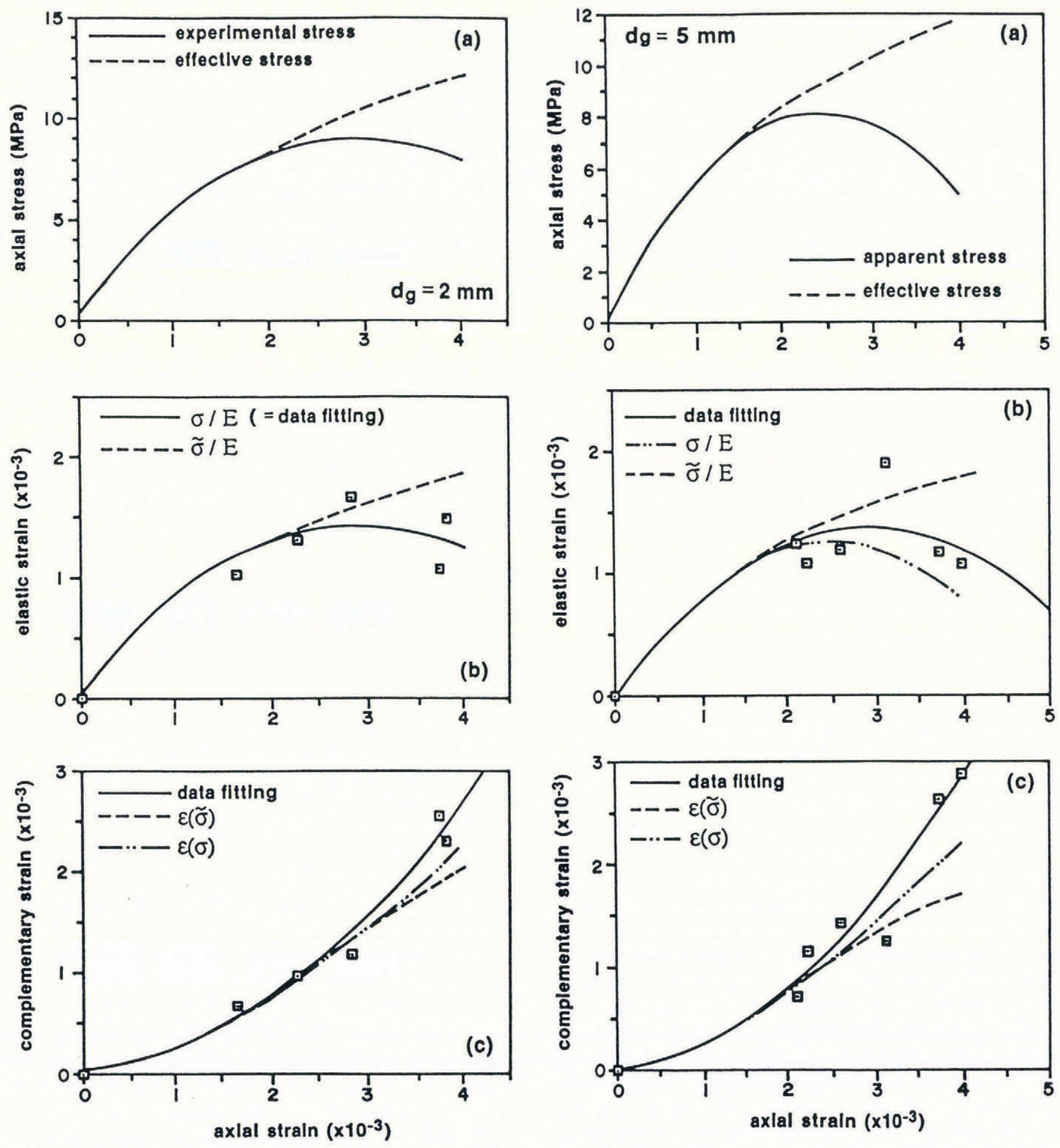

Fig. 9. Comparison between experiment and theory, using the concept of effective stress, for fine-grained ice tested in uniaxial compression. In graph (a), experimental stress and effective stress are plotted versus strain. In graph (b), the elastic component is concerned: data points are plotted in conjunction with a fitting curve; the curve $\varepsilon^{\mathrm{e}}(\sigma)$ is calculated using the model, and the curve $\varepsilon^{\mathrm{e}}(\sigma)$ is followed by that of an undamaged specimen which has undergone the stress of $\sigma(t)$. Graph (c) is related to the complementary component.

Fig. 10. Comparison between experiment and theory, using the concept of effective stress, for coarse-grained ice tested in uniaxial compression. Presentation is the same as in Figure 9.

of granular ice. We have shown that the role of confining pressure is to inhibit crack growth and crack interaction, and to shift the ductile-brittle transition towards higher strain rates. For $\dot{\varepsilon}<10^{-4} \mathrm{~s}^{-1}$, an increase in confining pressure results in a drastic reduction of the cracking activity, and makes ice essentially ductile. For $\dot{\varepsilon}>10^{-4} \mathrm{~s}^{-1}$, the peak stress is characterized by a population of cracks with length comparable to the mean grain-size, and with a density of 1 crack per grain, regardless of the confining 
pressure. The crucial role of cracks in relation to the behavior law is exhibited by the strong increase in strength with confining pressure. For $\dot{\varepsilon}>10^{-3} \mathrm{~s}^{-1}$, the brittle failure exhibited by the specimens in uniaxial compression was limited or even impeded by the application of a confining pressure.

The evolution of the elastic and the complementary strain components with the stress-strain history was investigated in uniaxial compression tests at $\dot{\varepsilon}=5 \times$ $10^{-4} \mathrm{~s}^{-1}$ by measuring recovery strain during relaxation. We applied the concept of effective stress to incorporate the effect of damage on these components. Although tests are preliminary, we have shown that the use of a single damage variable is not satisfactory. More tests are needed before establishing how microcracks specifically affect the elastic, delayed elastic and viscous strain components. The next step will be the formulation of damage evolution.

\section{ACKNOWLEDGEMENTS}

This work was supported by the Centre National de la Recherche Scientifique, Département des Sciences Physiques pour l'Ingénieur (France), and the Ministère de la Recherche, Mission Scientifique et Technique (France). We wish to thank E. M. Schulson and S.J. Jones for constructive comments on this work. We are grateful to M. Ricard, who designed the triaxial cell and provided technical assistance during the tests. We are also very grateful to the Institute for Marine Dynamics (St. John's, Newfoundland, Canada) where part of this work was written.

\section{REFERENCES}

Ashby, M. F. and P. Duval. 1985. The creep of polycrystalline ice. Cold Reg. Sci. Technol., 11(3), 285-300.

Chaboche, J.L. 1988. Continuum damage mechanics. Part 1. General concepts. J. Appl. Mech., 55, 5964.

Cole, D. M. 1986. The effect of grain size on the internal fracturing in polycrystalline ice. CRREL Rep. 86-5.

Cole, D. M. 1987. Strain-rate and grain-size effects in ice. J. Glaciol., 33(115), 274-280.

Cole, D. M. 1991. Microfracture and the compressive failure of polycrystalline ice. In Proceedings of IUTAM/IAHR Symposium on Ice Structure Interaction, St John's (NF, Canada), August 14-17, 1989. Berlin, etc., Springer-Verlag, 231-243.

Cole, D. M. and W. F. St Lawrence. 1984. Acoustic emission from ice. In Hardy, H. R., Jr and F. W. Leighton, eds. Third International Symposium on Acoustic Emission and Microseismic Activity in Geologic Structures and Materials. Philadelphia, PA, Pennsylvania State University Press.

Dieter, G.E. 1976. Mechanical metallurgy. New York, McGraw-Hill.

Gold, L.W. 1970. Process of failure in ice. Can. Geotech. J., 7(4), 405-413.

Gold, L.W. 1971. The failure of ice. In I.A.H.R. Symposium: Ice and its Action on Hydraulic Structures, Reykjavik, Iceland, 7-10 September
1970. Delft, International Association for Hydraulic Research, Paper 5.1.

Jaeger, J. C. and N. G. W. Cook. 1984. Fundamentals of rock mechanics. Third edition. London, etc., Chapman and Hall.

Jones, S. J. 1978. Triaxial testing of polycrystalline ice. In Proceedings of the Third International Conference on Permafrost, July 10-13, 1978, Edmonton, Alberta, Canada. Vol. 1. Ottawa, National Research Council of Canada, 671-674.

Jones, S.J. 1982. The confined compressive stress of polycrystalline ice. J. Glaciol., 28(98), 171-177.

Jones, S. J. and H. A. M. Chew. 1983. Effect of sample and grain size on the compressive strength of ice. Ann. Glaciol., 4, 129-132.

Kalifa, P., P. Duval and M. Ricard. 1989. Crack nucleation in polycrystalline ice under compressive stress states. In Sinha, N. K., D.S. Sodhi and J.S. Chung, eds. Proceedings of the Eighth International Conference on Offshore Mechanics and Arctic Engineering (OMAE), The Hague, Netherlands, March 19-23, 1989. Vol. 4. Arctic and polar technology. New York, American Society of Mechanical Engineers, 13-21.

Karr, D. G. and K. Choi. 1989. A three-dimensional constitutive damage model for polycrystalline ice. Mechanics of Materials, 8, 55-66.

Lasonde, G.I., M. C. Gies and E. M. Schulson. 1988. The effects of end conditions on the strength of ice under compression. In Saeki, H. and K. Hirayama, eds. Proceedings, the 9th International Symposium on Ice, 23-27 August, 1988, Sapporo, Japan. Vol. 1. Delft, International Association for Hydraulic Research. Committee on Ice Problems, 99-108.

Le Gac, H. and P. Duval. 1980. Constitutive relations for the non elastic deformation of polycrystalline ice. In Tryde, P., ed. International Union of Theoretical and Applied Mechanics. Physics and Mechanics of Ice, Symposium Copenhagen, August 610, 1979. Berlin, etc., Springer-Verlag, 51-59.

McKenna, R. F., J. Meyssonnier and I. J. Jordaan. 1989. Peak pressures from a damage model for ice in compression. In Sinha, N. K., D. S. Sodhi and J. S. Chung, eds. Proceedings of the Eighth International Conference on Offshore Mechanics and Arctic Engineering (OMAE), The Hague, Netherlands, March 19-23, 1989. Vol. 4. Arctic and polar technology. New York, American Society of Mechanical engineers, 67-73.

Mellor, M. and D. M. Cole. 1982. Deformation and failure of ice under constant stress or constant strain-rate. Cold Reg. Sci. Technol., 5(3), 201-219.

Meyssonnier, J. and P. Duval. 1989. Creep behavior of damaged ice under uniaxial compression: a preliminary study. In Axelsson, K. B. E. and L. A. Fransson, eds. POAC 89. The 10th International Conference on Port and Ocean Engineering under Arctic Conditions, June 12-16, Luleå, Sweden. Proceedings. Vol. 1. Luleå, Tekniska Högskolan i Luleå, 225-234.

Murrell, S. A.F., P.S. Sammonds and M. A. Rist. 1991. Strength and failure of pure ice and multi-year 
sea ice under triaxial loading. In Proceedings of IUTAM/IAHR Symposium on Ice/Structure Interaction, St John's (NF, Canada), August 14-17, 1989. Berlin, etc., Springer-Verlag, 339-361.

St Lawrence, W. F. and D. M. Cole. 1982. Acoustic emission from polycrystalline ice. Cold Reg. Sci. Technol., 5(3), 183-199.

Schulson, E. M. 1987. The fracture of ice Ih. J. Phys. (Paris), 48, Colloq. Cl, 207-220. (Supplément au 3.)

Schulson, E. M. 1991. The tensile and compressive fracture of ice. In Proceedings of IUTAM/IAHR Symposium on Ice/Structure Interaction, St John's (NF, Canada), August 14-17, 1989. Berlin, etc., Springer-Verlag, 165-187.

Schulson, E. M. and N.P. Cannon. 1984. The effect of grain size on the compressive strength of ice. In IAHR Ice Symposium, Hamburg, August 27-31, 1984. Proceedings. Vol. 1. Hamburg, Hamburgische Schiffbau-Versuchsanstalt, 29-38.

Sinha, N.K. 1984. Intercrystalline cracking, grainboundary sliding, and delayed elasticity at high temperatures. J. Mater. Sci., 19(2), 359-376.

Sinha, N.K. 1988. Crack-enhanced creep in polycrystalline material: strain-rate sensitive strength and deformation of ice. J. Mater. Sci., 23(12), 4415-4428.

Sjölind, S. G. 1987. A constitutive model for ice as a damaging visco-elastic material. Cold Reg. Sci. Technol., 14(3), 247-262.

Stone, M., I. J. Jordaan, S. J. Jones and R. F. McKenna. 1989. Damage of isotropic polycrystalline ice under moderate confining pressures. In Axelsson, K. B. E. and L.A. Fransson, eds. POAC 89. The 10th International Conference on Port and Ocean Engineering under Arctic Conditions, June 1216, Luleå, Sweden. Proceedings. Vol. 1. Luleå, Tekniska Högskolan i Luleå, 408-419.

Sunder, S. S. and M.S. Wu. 1989. A multiaxial differential model of flow in orthotropic polycrystalline ice. Cold Reg. Sci. Technol., 16(3), 223-235.

Weertman, J. 1969. Effect of cracks on creep rate. Trans. A.S.M., 62, 502-511.

The accuracy of references in the text and in this list is the responsibility of the authors, to whom queries should be addressed.

\section{APPENDIX}

\section{CALCULATION OF THE EFFECTIVE STRESS AND OF THE CORRESPONDING STRAIN COMPONENTS}

The principle of strain equivalence adopted here states that the strain response of the damaged specimen is derived by substituting the applied stress $\sigma$ with the effective stress $\tilde{\sigma}$ in the constitutive equation for the virgin specimen, i.e. Equation (1).

To solve this equation numerically, we split the strain history $\varepsilon(t)$ into $n$ intervals of constant length $\Delta \varepsilon=$ $10^{-5}$. $n$ is given by $n=\varepsilon_{\mathrm{f}} / \Delta \varepsilon$ where $\varepsilon_{\mathrm{f}}$ is the strain at the end of the test. The duration $\Delta t_{i}$ of the $i$ th time interval $\left[t_{i}-1, t_{i}\right]$ is a function of strain rate. In the uniaxial tests, strain rate was a constant and $\Delta t_{i}$ is merely $\Delta t_{i}=\Delta \varepsilon / \dot{\varepsilon}$, $\forall i$. At the instant $t_{i}$, Equation (1) is

$$
\begin{aligned}
& \varepsilon\left(t_{i}\right)=i \Delta \varepsilon \\
& =\frac{\tilde{\sigma}\left(t_{i}\right)}{\mathrm{E}_{\mathrm{e}}}+\exp (-\alpha t) \int_{0}^{t_{i}} \frac{\tilde{\sigma}(t)}{\eta} \exp (\alpha t) \mathrm{d} t+A \int_{0}^{t_{i}} \tilde{\sigma}(t)^{3} \mathrm{~d} t
\end{aligned}
$$

or

$$
\varepsilon\left(t_{i}\right)=\varepsilon^{\mathrm{e}}\left(t_{i}\right)+\varepsilon^{\mathrm{d}}\left(t_{i}\right)+\varepsilon^{\mathrm{v}}\left(t_{i}\right) .
$$

We make the assumption that the effective stress is constant over the $i$ th interval and equal to $\sigma_{i}=\sigma\left(t_{i}\right)$. We can then write differently each strain component. The elastic component is:

$$
\varepsilon^{\mathrm{e}}\left(t_{i}\right)=\tilde{\sigma}_{i} / \mathrm{E}_{\mathrm{e}}
$$

The delayed elastic component can be expressed as:

$$
\begin{gathered}
\varepsilon^{\mathrm{d}}\left(t_{i}\right)=\exp \left(-\alpha t_{i}\right) \int_{0}^{t_{i}} \frac{\tilde{\sigma}(t)}{\eta} \exp (\alpha t) \mathrm{d} t \\
=\exp \left(-\alpha t_{i}\right)\left\{\int_{0}^{t_{i} 1} \frac{\tilde{\sigma}(t)}{\eta} \exp (\alpha t) \mathrm{d} t\right. \\
\left.\quad+\int_{t_{i} 1}^{t_{i}} \frac{\tilde{\sigma}(t)}{\eta} \exp (\alpha t) \mathrm{d} t\right\} \\
=\exp \left(-\alpha t_{i}\right)\left\{\exp \left(\alpha t_{i-1}\right) \varepsilon^{\mathrm{d}}\left(t_{i-1}\right)\right. \\
\left.\quad+\frac{\tilde{\sigma}_{i}}{\eta} \int_{t_{i 1}}^{t_{i}} \exp (\alpha t) \mathrm{d} t\right\} .
\end{gathered}
$$

Then,

$$
\varepsilon^{\mathrm{d}}\left(t_{i}\right)=\exp \left(-\alpha \Delta t_{i}\right) \varepsilon^{\mathrm{d}}\left(t_{i-1}\right)+\frac{\tilde{\sigma}_{i}}{\mathrm{E}_{\mathrm{d}}}\left[1-\exp \left(-\alpha \Delta t_{i}\right)\right] .
$$

Finally, the viscous component is:

$$
\begin{aligned}
\varepsilon^{\mathrm{v}}\left(t_{i}\right)=\mathrm{A} \int_{0}^{t_{i}} \tilde{\sigma}(t)^{3} \mathrm{~d} t & =\varepsilon^{\mathrm{v}}\left(t_{i-1}\right)+A \int_{t_{i 1}}^{t_{i}} \tilde{\sigma}(t)^{3} \mathrm{~d} t \\
& =\varepsilon^{\mathrm{v}}\left(t_{i-1}\right)+A \tilde{\sigma}_{i}^{3} \Delta t_{i} .
\end{aligned}
$$

Substituting Equations (A3), (A5) and (A6) into Equation (A2), and using the definition of $\Delta \varepsilon$,

$$
\begin{gathered}
\varepsilon^{\mathrm{e}}\left(t_{i-1}\right)+\left[1-\exp \left(-\alpha \Delta t_{i}\right)\right] \varepsilon^{\mathrm{d}}\left(t_{i-1}\right)+\Delta \varepsilon \\
=\frac{\tilde{\sigma}_{i}}{\mathrm{E}_{\mathrm{e}}}+\frac{\tilde{\sigma}_{i}}{\mathrm{E}_{\mathrm{d}}}\left[1-\exp \left(-\alpha \Delta t_{i}\right)\right]+\mathrm{A} \tilde{\sigma}_{i}^{3} \Delta t_{i} .
\end{gathered}
$$

This is an equation of the third degree in $\tilde{\sigma}_{i}$. The condition at $t_{0}=0$ is $\varepsilon_{\mathrm{d}}\left(t_{0}\right)=0$ and $\varepsilon_{\mathrm{e}}\left(t_{0}\right)=\tilde{\sigma}\left(t_{0}\right) / \mathrm{E}_{\mathrm{e}} . \quad \tilde{\sigma}\left(t_{0}\right)$ is different from 0 when a pre-load was applied before starting the test. Equation (A7) has one real solution, which is found by an approximation method. Then, $\tilde{\sigma}_{i}$ is replaced in Equations (A3), (A5) and (A6) to give the values of the strain components at $t=t_{i}$. 